\title{
Treatment outcomes of Gene Xpert positive tuberculosis patients in KwaMashu Community Health Centre, KwaZulu-Natal, South Africa: A retrospective review
}

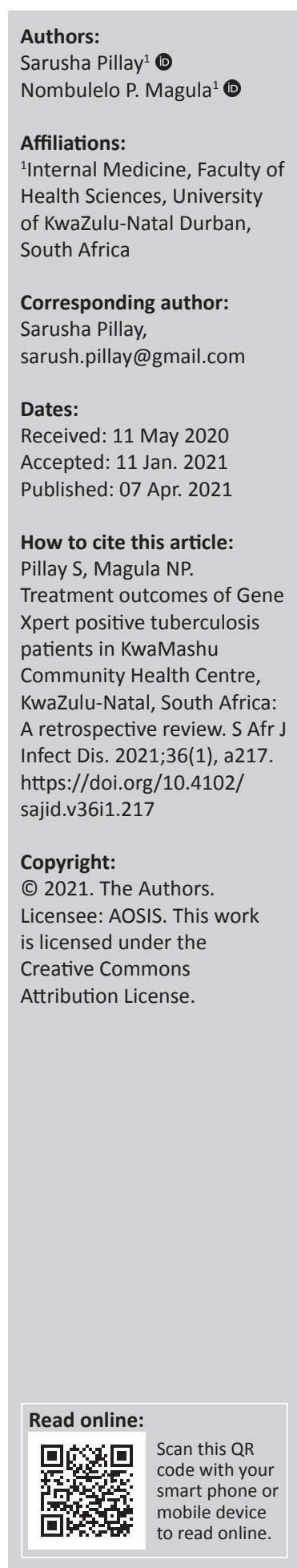

Background: We sought to investigate the relationship between tuberculosis (TB) treatment outcomes and its predictors in the KwaMashu region in KwaZulu-Natal (KZN). This area is currently a hotbed for TB and human immunodeficiency virus (HIV) co-infection.

Method: A retrospective study design was adopted to characterise adult patients diagnosed with Gene Expert (GXP) positive pulmonary TB from 01 January 2016 to 31 December 2017. Tuberculosis treatment outcomes were assessed after two months and five months according to the standard World Health Organization (WHO) criteria. Multiple logistic regression analysis was used to calculate the odds ratio (OR) of the possible determinants associated with unsuccessful treatment outcomes.

Results: Amongst the 596 patients diagnosed, 57.4\% (95\% confidence interval [CI]: 53.3-61.4; 342 of 596) had successful treatment outcomes. Of these reported cases, $88.89 \%(85.1-92.0 ; 304$ of 342) were cured. For the unsuccessful treatment outcomes, 52.4\% (46.0-58.6; 133 of 254) patients were lost to follow-up, $20.9 \%(16.0-26.4 ; 53$ of 254$)$ failed treatment, $1.2 \%(0.2-3.4 ; 3$ of 254) died and $25.6 \%(20.3-31.4 ; 65$ of 254) of the patients could not be accounted for. Patients with unknown HIV status were more likely to have unsuccessful treatment outcomes (adjusted $\mathrm{OR}[\mathrm{aOR}]=4.94$ [1.83-13.36]). Patients who had sputum conversion at 2 months $(\mathrm{aOR}=1.94$ [1.27-2.96]) were significantly more likely to exhibit unsuccessful treatment outcomes.

Conclusion: Treatment success rate was $57.4 \%$ which was below the target set by the WHO. This underscores the urgent need to strengthen treatment adherence strategies to improve outcomes, especially in high HIV burden settings.

Keywords: tuberculosis; sputum conversion; unsuccessful treatment outcomes; Gene Xpert; HIV.

\section{Introduction}

In 2018, an estimated 10 million people globally were diagnosed with tuberculosis (TB) with the burden being heterogeneous amongst countries. Of these patients 1.2 million (11\%) were coinfected with human immunodeficiency virus (HIV). The worldwide TB mortality was 1.2 million amongst HIV-negative individuals, with 251000 deaths being reported in HIV-positive patients. ${ }^{1}$ In a recent review of HIV deaths, TB was found to be prevalent in $37 \%$ of the deaths; however, in half of the cases, autopsy results indicated that these cases were not diagnosed by the time of death. ${ }^{2}$ The highest TB burden has previously been reported in men (aged $\geq 15$ years) with 57\% being diagnosed in 2018. Comparatively women accounted for $32 \%$ of the cases whilst children (aged < 15 years) accounted for 11\%. ${ }^{1}$ Geographically, 30 high TB burden countries collectively accounted for $87 \%$ of the world's cases in $2018 .{ }^{3}$ South Africa has featured amongst the top twothirds of the countries with the highest incidence of TB globally, with 781 cases per 100000 being reported in $2016 .^{4}$

To address this silent burden, considerable efforts have been mounted in the past decade to improve TB treatment outcomes and cure rates in South Africa. However, South Africa's national treatment's success rate of $76 \%$ is still below the expected World Health Organization (WHO) success rate of $90 \%$. Furthermore, the country did not achieve the highly ambitious millennium development goals (MDGs) target of halving TB prevalence and mortality rate. ${ }^{5}$ Coincidentally, in 2017 , South Africa reported an incidence of 322000 TB cases; of these cases, 193000 (60\%) were HIV positive. 
This underscores the need to continually strengthen existing TB control initiatives and address its comorbidities in the province.

There has been a steady decline in the incidence rate of TB in South Africa, with 690 per 100000 cases reported in 2012 compared with 520 per 100000 in 2015. ${ }^{6}$ In 2015, KwaZulu-Natal (KZN) had the second highest incidence rate of TB of 685 per 100000 population. However, the most notable decline in the incidence rate has been in KZN over 5 years with a decrease from 1185 to 685 per 100000 population between 2011 and 2015, respectively. ${ }^{7}$ In 2017, the incidence cases in KZN were 58117, with almost half, 23059, cases reported from eThekwini Municipality.

Despite a notable decline in the $\mathrm{TB}$ incidence rate both globally and within South Africa, TB still ranks in the top 10 causes of death nationally and worldwide, especially in people living with HIV. ${ }^{8}$ Between 2014 and 2016, TB was the leading cause of death in South Africa. ${ }^{9}$ Being a curable disease still claims 4400 lives daily. In an attempt to control the global burden of disease in 2000, the United Nations MDGs aimed to 'Stop the spread and reverse the incidence of the global TB epidemic by 2015'. This goal was achieved between 2000 and 2013, and an estimated 37 million lives were saved. ${ }^{10}$ Between 2000 and 2014, the annual incidence rate of TB fell by 1.5\%; the Stop TB Partnership which aimed by 2015 to reduce the TB prevalence and mortality rates by $50 \%$ compared with 1990 was not achieved worldwide. ${ }^{11}$

As per the $\mathrm{WHO}$, TB treatment outcomes should be assessed annually at both national and district levels. ${ }^{11}$

Knowledge gaps remain on $\mathrm{TB}$ treatment outcomes and how they differ by the socio-economic factors in rural settings in KZN. Using routinely captured demographic and clinical characteristics of TB patients presenting at KwaMashu Community Health Centre we sought to evaluate treatment outcomes in a high-risk population group and identify determinants for unsuccessful treatment. This will assist in achieving the Stop TB 90/90/90 targets and also assist South Africa in achieving a $90 \%$ success rate.

\section{Methods \\ Study setting}

This was a facility-based retrospective study conducted in KwaMashu Community Health Centre.

KwaMashu Community Health Centre is situated in KwaMashu township ward 45 of the eThekwini district, KZN province, South Africa. The centre offers health services to the community of KwaMashu. It has a total of 25 beds. Currently, the centre serves mainly KwaMashu community and surrounding areas, with a catchment population of approximately 750000 people. It is also a referral centre for six satellite clinics, 11 mobile clinics and other facilities in Phoenix, Inanda, Ntuzuma, Newlands East and Newlands West, Lindelani, and Parlock. In 2012-2013, the Northern district was considered a 'hot spot' for the prevalence of HIV, which was estimated at $39 \%$. $^{12,13}$

\section{Study design and population}

This was a retrospective record review of routinely collected data of patients presenting at the KwaMashu Community Health Centre. Demographic and clinical data were retrieved primarily from individual treatment files. Other data sources included provincial TB registers, patient treatment cards and laboratory registers.

Individual patient notes were reviewed to supplement missing data or resolve discrepancies. The study population composed of adult patients (12 years and above) with a treatment outcome recorded between 01 January 2016 and 31 December 2017.

Tuberculosis treatment outcomes were reported and recorded according to the defined WHO outcome categories. ${ }^{14}$ Deidentified patient data, including socio-economic and clinical characteristics were collected on a pretested standardised form and entered in an Excel 2013 (Microsoft Corporation, Redmond, USA) spreadsheet. Two individuals independently cross-checked each entry for logical inconsistencies, invalid codes, omissions and improbable data by tabulating, summarising and plotting variables with missing observations being excluded systematically.

\section{Key terms in accordance to World Health Organization definitions and reporting framework for tuberculosis}

\section{Cured}

An initially sputum smear-positive patient whose sputum smear or culture is negative at or one month prior to the completion of TB treatment and on at least one previous occasion at least 30 days prior.

\section{Treatment completed}

A patient whose baseline sputum was positive and who has completed anti-TB treatment without evidence of failure but for whom sputum smear or culture results are not available in the last month of treatment and on at least one previous occasion.

\section{Treatment success}

The sum of patients who were declared 'cured' and those who had 'completed' treatment.

\section{Treatment failure}

A patient whose sputum smear or culture is positive at the fifth month of treatment or later during the course of treatment. Excluded in this definition are patients found to have multidrug-resistant TB at any point of time during the treatment. 


\section{Treatment defaulter or lost to follow-up}

A patient who has been on treatment for at least four weeks and whose treatment was interrupted for two consecutive months or more.

\section{Died}

A patient who died because of TB or for any reason during the course of treatment.

\section{Transfer out}

A patient who started treatment and was transferred to another treatment unit and for whom the treatment outcome is not known at the time of evaluation of treatment results.

Successful treatment composed of TB patients who were cured and those who completed their treatment, whereas unsuccessful treatment outcomes are TB patients who died, failed treatment, were lost to follow-up or not evaluated.

\section{Statistical analysis}

Data were analysed in STATA 15 (Stata Corp LP, College Station, TX, USA). Summary statistics were presented, with continuous variables presented with their mean and standard deviation (SD), whereas categorical variables summarised as counts and proportions (\%). A univariate and multivariate logistic regression models were used to evaluate the relationship between unsuccessful treatment outcome (dependent variable) and the selected demographic and clinical variables. The variables examined were gender, HIV status, age, antiretroviral treatment (ART) uptake, diabetes mellitus and smear microscopy results. To determine the effect of these variables on unsuccessful treatment, unadjusted and adjusted odds ratios (aORs), 95\% confidence interval $(\mathrm{CI})$ and $p$-value were used to assess the associative strength for each predictor with a two-sided $p<0.05$ deemed statistically significant.

\section{Ethical considerations}

Ethical clearance and approval for the study was provided by the Biomedical Research Committee (BREC) in association with the University of KZN (BREC No. BE509/16). Patients' records were anonymised and deidentified before analysis with strict confidentiality of patient information prioritised.

\section{Results}

\section{Study population}

A total of 596 patients' records were considered over the study period. The largest proportion of patients reported were males $63.9 \%(381 / 596)$, females were $36.1 \%(215 / 596)$. A total of $360(60.4 \%, 95 \%$ CI: 56.3-64.4) of the patients examined were HIV positive. Majority of the HIV patients $69.4 \%$ (95\% CI 64.4-74.2; 250/360) were reported as being on ART. The 30-39 age range had the highest percentage
(34.2\%) of TB cases, followed by the 20-29 age range with (32.2\%), 40-49 age range with $15.9 \%, 50-59$ range with $7.6 \%$, below 20 with $6.0 \%$ and above 60 with $4.0 \%$ (Table 1 ).

\section{Treatment outcomes}

Treatment outcomes of new smear positive pulmonary TB patients as per the standard WHO reporting criteria are shown in Table 2.

Out of the 596 patients included in the study $51.01 \%(n=304)$ were cured, $6.38 \%(n=38)$ completed their treatment, $8.89 \%$ $(n=53)$ had treatment failure at five months, $22.32 \%(n=133)$ were lost to follow-up, $0.50 \%(n=3)$ died and $10.91 \%(65 / 596)$ of the patients' treatment outcomes could not be accounted for (Table 3).

Although not statistically significant, male patients $(\mathrm{OR}=1.04$ [0.73-1.49]), patients with HIV (OR = 1.25 [0.85-1.82]), and patients between 30 and 39 years $(\mathrm{OR}=1.07$ [0.50-2.2]7) and patients above 60 years $(\mathrm{OR}=1.50$ [0.47-4.76]) were more likely to have unsuccessful treatment outcomes. On the contrary, patients with unknown HIV status $(\mathrm{OR}=$ 2.60 [1.32-5.14]) and those who had their sputum conversion at 2 months $(\mathrm{OR}=1.88[1.27-2.78])$ were more likely to have unsuccessful treatment outcomes.

Multiple logistic regression analysis was used to jointly explore the determinants of unsuccessful treatment outcomes in the study cohort. The independent determinants for unsuccessful treatment were gender, HIV status, ART, age, diabetes and sputum conversion at two months. After adjusting for possible confounding factors, patients with unknown HIV status $(\mathrm{aOR}=4.94$ [1.83-13.36] $)$ and patients who had their sputum conversion at 2 months $(\mathrm{aOR}=1.94$

TABLE 1: Demographic characteristics of tuberculosis patients attending KwaMashu Community Health Centre, KwaZulu-Natal, South Africa.

\begin{tabular}{|c|c|c|c|}
\hline \multirow[t]{2}{*}{ Patient's characteristics } & \multirow[t]{2}{*}{ Variable } & \multicolumn{2}{|c|}{ Patients } \\
\hline & & $n$ & $\%$ \\
\hline \multirow[t]{2}{*}{ Gender } & Male & 381 & 63.9 \\
\hline & Female & 215 & 36.1 \\
\hline \multirow[t]{3}{*}{ HIV status } & Positive & 360 & 60.4 \\
\hline & Negative & 168 & 28.2 \\
\hline & Unknown & 68 & 11.4 \\
\hline \multirow[t]{3}{*}{$\mathrm{ART}(n=360)$} & Yes & 250 & 69.4 \\
\hline & No & 99 & 27.5 \\
\hline & Unknown & 11 & 3.1 \\
\hline \multirow[t]{6}{*}{ Age (years) } & $<20$ & 36 & 6.0 \\
\hline & $20-29$ & 192 & 32.2 \\
\hline & $30-39$ & 204 & 34.2 \\
\hline & $40-49$ & 95 & 15.9 \\
\hline & $50-59$ & 45 & 7.6 \\
\hline & $>60$ & 24 & 4.0 \\
\hline \multirow{2}{*}{$\begin{array}{l}\text { Smear microscopy } \\
\text { ( } 2 \text { months) }\end{array}$} & Yes & 388 & 65.1 \\
\hline & No & 208 & 34.9 \\
\hline \multirow{3}{*}{$\begin{array}{l}\text { Smear microscopy } \\
\text { (5 months) }\end{array}$} & Yes & 257 & 43.1 \\
\hline & No & 337 & 56.5 \\
\hline & Unknown & 2 & 0.4 \\
\hline
\end{tabular}

HIV, human immunodeficiency virus; ART, antiretroviral therapy. 
TABLE 2: Treatment outcomes of new smear positive pulmonary tuberculosis patients in KwaMashu Community Health Centre, KwaZulu-Natal, South Africa, as per the standard criteria $(N=596)$.

\begin{tabular}{lcr}
\hline Treatment outcomes & \multicolumn{2}{c}{ Patients } \\
\cline { 2 - 3 } & $\boldsymbol{n}$ & $\%$ \\
\hline Successful & 304 & 51.01 \\
Cure & 38 & 6.38 \\
Treatment completed & 254 & 42.62 \\
Unsuccessful & 53 & 8.89 \\
Treatment failure & 133 & 22.32 \\
Treatment defaulter & 3 & 0.50 \\
Died & 65 & 10.91 \\
Unaccountable & $\mathbf{3 4 2}$ & $\mathbf{5 7 . 3 8}$ \\
\hline Total & &
\end{tabular}

[1.27-2.96]) were significantly $(p<0.05)$ more likely to have unsuccessful treatment outcomes (Table 4).

\section{Discussion}

In this retrospective study, we assessed TB treatment outcomes and the plausible determinants of unsuccessful outcomes. The study findings revealed a higher percentage of TB cases amongst the age groups of 20-29 and 30-39. This is consistent with studies done in Mpumalanga South Africa, Northeast and Central Ethiopia. ${ }^{15,16}$ In our study, the disproportionate burden in the age groups 20-29 and 30-39 could be as a result of greater mobility attendant to this demographic group occasioned by social and economic ambitions. A further contributing factor within the South African population could be because of the high prevalence of HIV co-infection amongst this age groups. ${ }^{17}$ However, these findings are in contrast to studies in China, Cambodia and Vietnam where patients older than 55 years had low incidence of TB..$^{18,19}$ Diabetes, concomitant malignancies and other co-morbidities in the elderly have previously been identified as predisposing for the elderly. ${ }^{20}$ Further evidence alludes age as an important factor in determining TB treatment outcomes. ${ }^{19,21,22,23}$ However, in our cohort, no significant relationship was found between all the age groups and unsuccessful treatment outcome.

We observed a higher proportion of TB amongst all cases to be higher amongst males than females.

A finding similar to other international studies conducted in Malaysia $(70.24 \%),{ }^{24}$ Cambodia, China, Vietnam (69.1\%), ${ }^{18}$ Ethiopia $(61.3 \%)^{25}$ and Pakistan $(51.7 \%)^{26}$ which have noted a similar trend. This could be attributed to differential susceptibility to TB because of biological orientation, lower female notification rates as a result of socio-economic and cultural barriers in healthcare access and high exposure risk in males because of their high-risk exposure, substance abuse and social engagement. ${ }^{27}$ In addition, young adults (30-39 years) and older adults (above 60 years) represent a vulnerable population cohort with unique challenges with regard to TB treatment.

For the younger population, this might be attributed to poor adherence to treatment and behaviours/lifestyle choices that may make them more vulnerable to unsuccessful outcomes. ${ }^{28,29}$

A large proportion of the patients in this study (60.4\%) were HIV positive, consistent with HIV and TB coinfection rates in South Africa. ${ }^{1}$ Cluster of differentiation 4 (CD4) cell counts and viral loads were not known in many patients. Of note, only $69.4 \%$ of the HIV-positive patients were on ART. This is of concern as according to the Joint United Nations Programme on HIV/AIDS (UNAIDS) strategy to end HIV as a public health threat by $2030,90 \%$ of all people living with HIV should know their HIV status, $90 \%$ of all patients diagnosed with HIV infection should receive sustained ART and $90 \%$ of all people receiving ART should have viral suppression by $2020 .{ }^{30}$ With the institution of the 'test and treat' campaign in 2016 together with the national TB guidelines, it is of concern that there is a large number of patients who are not on ART. ${ }^{31,32}$

Our study also revealed that $11 \%$ of patients were also unaware of their HIV status.

One of the determinants of an unsuccessful treatment outcome in this study was patients who did not know their HIV status. An opt-out approach for HIV testing should become a routine procedure as opposed to an opt in approach. This would result in less patients with HIV/TB co-infection being missed and allow for earlier diagnosis and treatment. ${ }^{33,34}$ Patient diagnosed and initiated on treatment during the advanced stages of HIV could also have affected treatment outcomes. ${ }^{35}$

Previous evidence suggests that patients with higher CD4 cell counts and who are on ART have been shown to have more successful outcomes. ${ }^{36}$ Tuberculosis and HIV treatment in combination has been shown to improve treatment failure rates. ${ }^{21}$ For patients who are HIV and TB coinfected and on ART, the national rates have improved from $28 \%$ in 2011 to $89.1 \%$ in 2017.7 In comparison to the national standards, our study showed a large proportion of HIV positive patients who were not on treatment. Stronger initiatives aimed at HIV testing and commencement of treatment, especially in TB and HIV high-risk areas will need to be used to improve TB treatment outcome rates.

It is important to achieve and sustain acceptable levels of treatment success rates amongst TB patients. ${ }^{21,37}$ The overall treatment success rate based on sputum smear positive TB cases was $57.38 \%$. The cure rate was $51.01 \%$.

The treatment success rate obtained in our study is relatively higher than $40.6 \%$ in Uganda. ${ }^{38}$ However, this was still low compared with the WHO successful target rate of $90 \% .{ }^{39}$ Countries which have succeeded in making this target are Ethiopia (91.8\%) ${ }^{40}$ and China $(95.02 \%, 93.9 \%) .{ }^{41,42}$ A systemic review and meta-analysis conducted in seven Sub-Saharan Africa countries showed a total TB success rate of $76 \%{ }^{43}$ Two studies in Gauteng Province found success rates of 
TABLE 3: Clinical characteristics of tuberculosis patients in KwaMashu Community Health Centre, KwaZulu-Natal, South Africa, stratified by gender.

\begin{tabular}{|c|c|c|c|c|c|c|c|}
\hline \multirow[t]{3}{*}{ Patient's characteristics } & \multirow[t]{3}{*}{ Variable } & \multicolumn{4}{|c|}{ Patients } & \multicolumn{2}{|c|}{ Total } \\
\hline & & \multicolumn{2}{|c|}{ Male } & \multicolumn{2}{|c|}{ Female } & \multirow[t]{2}{*}{$n$} & \multirow[t]{2}{*}{$\%$} \\
\hline & & $\%$ & $95 \% \mathrm{Cl}$ & $\%$ & $95 \% \mathrm{Cl}$ & & \\
\hline \multirow[t]{6}{*}{ Age (years) } & $<20$ & 36 & $22.1-53.0$ & 64 & $47.0-77.9$ & 36 & 6.0 \\
\hline & $20-29$ & 58 & $51.2-65.1$ & 42 & $34.9-48.8$ & 192 & 32.2 \\
\hline & $30-39$ & 69 & $62.4-75.1$ & 31 & $24.9-37.6$ & 204 & 34.2 \\
\hline & $40-49$ & 72 & $61.6-79.8$ & 28 & $20.2-38.4$ & 95 & 15.9 \\
\hline & $50-59$ & 67 & $51.6-78.9$ & 33 & $21.0-48.4$ & 45 & 7.6 \\
\hline & $>60$ & 71 & $49.7-85.7$ & 29 & $14.3-50.3$ & 24 & 4.0 \\
\hline \multirow[t]{3}{*}{ HIV status } & Positive & 57 & $52.0-62.3$ & 43 & $37.7-48.0$ & 360 & 60.4 \\
\hline & Negative & 72 & $64.7-78.3$ & 28 & $21.7-35.3$ & 168 & 28.2 \\
\hline & Unknown & 79 & $68.1-87.5$ & 21 & $12.5-31.9$ & 68 & 11.4 \\
\hline \multirow[t]{3}{*}{ ART (HIV +ve) } & Yes & 56 & $49.7-62.1$ & 44 & $37.9-50.2$ & 250 & 69.4 \\
\hline & No & 61 & $50.6-69.7$ & 39 & $30.2-49.4$ & 99 & 27.5 \\
\hline & Unknown & 55 & $25.6-80.7$ & 46 & $19.3-74.4$ & 11 & 3.1 \\
\hline & Yes & 56 & $32.4-76.5$ & 44 & $23.5-67.6$ & 18 & 3.3 \\
\hline & Unknown & 0 & - & 1 & - & 1 & 0.2 \\
\hline \multirow[t]{3}{*}{ Smear microscopy result } & Negative & 61 & $54.6-67.1$ & 39 & $32.9-45.4$ & 236 & 39.6 \\
\hline & Positive & 69 & $62.5-74.0$ & 32 & $26.0-37.5$ & 251 & 42.1 \\
\hline & Unknown & 60 & $50.1-68.5$ & 40 & $31.5-49.9$ & 109 & 18.3 \\
\hline
\end{tabular}

HIV, human immunodeficiency virus; ART, antiretroviral therapy; Cl, confidence interval.

TABLE 4: Determinants of unsuccessful treatment outcome in KwaMashu Community Health Centre, KwaZulu-Natal, South Africa.

\begin{tabular}{|c|c|c|c|c|c|c|}
\hline \multirow[t]{2}{*}{ Variable } & \multicolumn{3}{|c|}{ Unadjusted odds ratio } & \multicolumn{3}{|c|}{ Adjusted odds ratio } \\
\hline & OR & $95 \% \mathrm{Cl}$ & $p$ & aOR & $95 \% \mathrm{Cl}$ & $p$ \\
\hline \multicolumn{7}{|l|}{ Gender } \\
\hline Female & - & - & - & - & - & - \\
\hline Male & 1.040 & $0.730-1.490$ & 0.814 & 1.020 & $0.660-1.570$ & 0.941 \\
\hline \multicolumn{7}{|l|}{ HIV status } \\
\hline Negative & - & - & - & - & - & - \\
\hline Unknown & 2.600 & $1.320-5.140$ & 0.006 & 4.940 & $1.830-13.360$ & 0.002 \\
\hline \multicolumn{7}{|l|}{ ART } \\
\hline No & - & - & - & - & - & - \\
\hline Yes & 0.840 & $0.590-1.190$ & 0.333 & 0.700 & $0.390-1.230$ & 0.213 \\
\hline Unknown & 0.670 & $0.270-1.700$ & 0.402 & 0.350 & $0.080-1.420$ & 0.140 \\
\hline \multicolumn{7}{|c|}{ Age (years) } \\
\hline Below 20 & - & - & - & - & - & - \\
\hline $30-39$ & 1.070 & $0.500-2.270$ & 0.862 & 1.110 & $0.420-2.930$ & 0.829 \\
\hline $40-49$ & 0.940 & $0.420-2.110$ & 0.880 & 0.960 & $0.340-2.720$ & 0.943 \\
\hline $50-59$ & 1.000 & $0.390-2.530$ & 1.000 & 1.230 & $0.390-3.930$ & 0.723 \\
\hline Above 60 & 1.500 & $0.470-4.760$ & 0.491 & 2.300 & $0.460-11.400$ & 0.309 \\
\hline \multicolumn{7}{|l|}{ Diabetes } \\
\hline No & - & - & - & - & - & - \\
\hline Yes & 0.990 & $0.370-2.700$ & 0.996 & 0.720 & $0.210-2.460$ & 0.602 \\
\hline \multicolumn{7}{|c|}{ Sputum conversion 2 months } \\
\hline No & - & - & - & - & - & - \\
\hline Yes & 1.880 & $1.270-2.780$ & 0.002 & 1.940 & $1.270-2.960$ & 0.002 \\
\hline
\end{tabular}

$\mathrm{Cl}$, confidence interval; HIV, human immunodeficiency virus; ART, antiretroviral treatment.

$80 \%{ }^{44}$ and $83.48 \% .^{2}$ The low TB success rate within our study is an indication of generally underperforming and failing TB programme in resource-constrained areas.

Other contributing factors might be our study's sample size, the study period, HIV status and healthcare quality.

A possible reason for the higher success rates obtained in the Gauteng studies may be the inclusion of all TB patients regardless of smear status, extrapulmonary TB and children.

Patients who were transferred out were also excluded from the Gauteng study. There was also a large default group in our cohort. A large pill burden associated with HIV and TB coinfection as well as patients starting to feel better after initial treatment commencement may have resulted in patients defaulting treatment. The KwaMashu 
district remains an impoverished community with a high rate of unemployment. Financial factors in terms of accessing healthcare facilities and attending follow-up visits may have also contributed to patients defaulting treatment.

A deeper understanding of factors associated with unsuccessful TB treatment outcomes can encourage appropriate interventions intended to reduce morbidity and mortality. ${ }^{42}$ In this study, loss to follow-up $22.32 \%(n=133)$ composed a major portion of the unsuccessful outcome. Significantly lower rates were noted in a primary healthcare facility in Johannesburg (11\%), ${ }^{44}$ Gauteng province $(5.4 \%)^{23}$ and Ethiopia (8.5\%). ${ }^{15}$ Age, gender and not being on ART have shown to increase the risk for lost to follow-up. ${ }^{23}$ Several reasons related to our study participants and the health centre may have contributed to the outcomes reported. It was noted in this study that patients were lost to follow-up because of patient relocation; attempts were made by healthcare workers to trace patients through home visits and telephonic consultations. Social issues including alcohol and drug abuse as well as psychiatric conditions also contributed to patients being lost to follow-up.

Sputum conversion at two months was significantly associated with unsuccessful TB treatment outcomes. These findings are inconsistent with studies widely reported in Western Cape, South Africa, ${ }^{45}$ Pakistan $^{26}$ and India. ${ }^{46} \mathrm{~A}$ possible reason for this could be that a large proportion of the unsuccessful outcomes in our study were because of patients who were lost to follow-up. Patients who had achieved sputum conversion at two months may have believed that they have been cured and thereafter defaulted further treatment and follow-up. Despite diabetes not showing a statistical significance relationship with treatment outcomes in our study, diabetes is known to reduce a patient's immune response, thus making them more susceptible in acquiring the infection as well as having poorer outcomes. ${ }^{47,48}$ Future treatment and monitoring programmes and strategies should aim to ensure that patients are followed up for the entire six months and that patients adhere strictly to treatment regimes.

\section{Study limitations}

This was a retrospective study in a rural health community that is bombarded with unmet health needs for HIV-infected patients presenting with possible $\mathrm{TB}$ and the inherent limitations of registry-based data. Information on important variables such as patients' CD4 count, education-level HIV risk factors and hospitalisation history was not identified. Study results should be applied with caution, as we were unable to verify HIV status or validate TB laboratory results. We were also not able to accurately link all our patients to the various outcomes. It is also possible that patients considered in our study might have been lost or misclassified in the present analysis.

\section{Conclusion}

Tuberculosis continues to be the most common presenting illness amongst people living with HIV in rural South Africa. The study findings showed the treatment success rate to be below the WHO target of 90\%. Information about determinants of unsuccessful treatment outcomes provides important insight for steering TB and HIV control initiatives to meet the needs of different age and risk groups in rural settings in South Africa. The study serves as a quality improvement indicator that can hopefully be extrapolated onto a bigger scale and promote similar studies to be undertaken in other provinces grappling with improving TB treatment outcomes.

\section{Acknowledgements}

The authors would like to thank the nursing staff at Kwamashu Community Health Centre, as well as the individuals who assisted with the data collection. The authors would also like to acknowledge Mr Neyere for his contribution

\section{Competing interests}

The authors declare that they have no financial or personal relationships that may have inappropriately influenced them in writing this article.

\section{Authors' contributions}

Both authors contributed to the conception and design of the study. S.P. was responsible for data collection and data entry. S.P. wrote the first draft of the article under the supervision by N.P.M. Both authors revised and approved the final manuscript.

\section{Funding information}

This research received no specific grant from any funding agency in the public, commercial or not-for-profit sectors.

\section{Data availability}

Raw data were generated at KwaMashu Community Health Centre. Derived data supporting the findings of this study are available from the corresponding author, S.P., upon reasonable request.

\section{Disclaimer}

The views and opinions expressed in this article are those of the authors and do not necessarily reflect the official policy or position of any affiliated agency of the authors.

\section{References}

1. Global tuberculosis report 2019. Geneva: World Health Organization (WHO); 2019.

2. Gupta RK, Lucas SB, Fielding KL, Lawn SD. Prevalence of tuberculosis in postmortem studies of HIV-infected adults and children in resource-limited settings: A systematic review and meta-analysis. AIDS. 2015;29(15):1987. https://doi. org/10.1097/QAD.0000000000000802 
3. Petersen E, Blumberg L, Wilson ME, Zumla A. Ending the global tuberculosis epidemic by 2030 - The Moscow declaration and achieving a major translational change in delivery of TB healthcare. Int J Infect Dis. 2017;65:156-158. https://doi. org/10.1016/j.ijid.2017.11.029

4. Country profiles for 30 high burden countries. Geneva: World Health Organization (WHO); 2018.

5. Gobal tuberculosis report 2014. Geneva: World Health Organization (WHO); 2014.

6. Kanabus A. Information about tuberculosis. London: Global Health Education (GHE); 2016.

7. Massyn N, Pillay Y, Padarath A. District heath barometer 2017/2018. Durban: Health Systems Trust; 2019.

8. Global health estimates 2016: Deaths by cause, age, sex, by country and by region, 2000-2026. Geneva: World Health Organization; 2018.

9. Mortality and causes of death in South Africa, 2016. Tshwane: Statistics South Africa; 2019.

10. Motala S, Ngandu S, Mti S, et al. Millennium development goals: Country report 2015. Tshwane: Statistics South Africa; 2016

11. The paradigm shift 2016-2020: Global plan to end tuberculosis 2015. Geneva: World Health Organization (WHO); 2015.

12. Ethekwini Municipality. Inanda, Ntuzuma, KwaMashu (INK) Nodal economic development profile. KwaZulu Natal: Department of Provincial and Local Government, Republic of South Africa; 2006.

13. Gabela M, Manivasen N, Dazel M, Dukie R. District health plan 2015/2016 Ethekwini health district KwaZulu-Natal. Department of Health: Province of KwaZulu-Natal; 2015

14. Treatment of tuberculosis guidelines. Geneva: World Health Organization (WHO); 2010.

15. Hamusse SD, Demissie M, Teshome D, Lindtjørn B. Fifteen-year trend in treatment outcomes among patients with pulmonary smear-positive tuberculosis and its determinants in Arsi Zone, Central Ethiopia. Glob Health Action. 2014;7(1):25382 https://doi.org/10.3402/gha.v7.25382

16. Belay M, Bjune G, Abebe F. Prevalence of tuberculosis, HIV, and TB-HIV coinfection among pulmonary tuberculosis suspects in a predominantly pastoralist area, Northeast Ethiopia. Glob Health Action. 2015;8(1):27949. https://doi org/10.3402/gha.v8.27949

17. Joint United Nationa programme on HIV/AIDS. Country factsheet. Geneva: United Nations (UN); 2018.

18. Hoa NB, Wei C, Sokun C, Lauritsen JM, Rieder HL. Characteristics of tuberculosis patients at intake in Cambodia, two provinces in China, and Viet Nam. 2011;11(1):367. https://doi.org/10.1186/1471-2458-11-367

19. Somma D, Thomas B, Karim F, et al. Gender and socio-cultural determinants of TB-related stigma in Bangladesh, India, Malawi and Colombia [Special section on gender and TB]. Int J Tuberc Lung Dis. 2008;12(7):856-866.

20. Negin J, Abimbola S, Marais BJ. Tuberculosis among older adults-time to take notice. Int J Infect Dis. 2015;32:135-137. https://doi.org/10.1016/j.ijid.2014. 11.018

21. Khazaei S, Roshanaei G, Saatchi M, Rezaeian S, Zahiri A, Bathaei SJ. The epidemiological aspects of tuberculosis in Hamadan province during 2005-2011. Int J Health Policy Manag. 2014;2(2):75. https://doi.org/10.15171/ijhpm.2014.18

22. Shahrezaei M, Maracy MR, Farid F. Factors affecting mortality and treatment completion of tuberculosis patients in Isfahan province from 2006 to 2011. Int Prev Med. 2015;6(1):91. https://doi.org/10.4103/2008-7802.165157

23. Berry KM, Rodriguez CA, Berhanu RH, et al. Treatment outcomes among children adolescents, and adults on treatment for tuberculosis in two metropolitan municipalities in Gauteng province, South Africa. BMC Public Health 2019;19(1):973. https://doi.org/10.1186/s12889-019-7257-4

24. Atif M, Sulaiman SAS, Shafie AA, Ali I, Asif M. Treatment outcome of new smea positive pulmonary tuberculosis patients in Penang, Malaysia. BMC Infect Dis. 2014;14(1):399. https://doi.org/10.1186/1471-2334-14-399

25. Gebrezgabiher G, Romha G, Ejeta E, Asebe G, Zemene E, Ameni G. Treatment outcome of tuberculosis patients under directly observed treatment short course and factors affecting outcome in Southern Ethiopia: A five-year retrospective study. PLoS One. 2016;11(2):e0150560. https://doi.org/10.1371/journal.pone. 0150560

26. Atif M, Anwar Z, Fatima RK, Malik I, Asghar S, Scahill S. Analysis of tuberculosis treatment outcomes among pulmonary tuberculosis patients in Bahawalpur, Pakistan. BMC Res Notes. 2018;11(1):370. https://doi.org/10.1186/s13104-0183473-8
27. Neyrolles O, Quintana-Murci L. Sexual inequality in tuberculosis. PLoS Med. 2009;6(12):e1000199. https://doi.org/10.1371/journal.pmed.1000199

28. Roadmap towards ending tuberculosis in children and adolescents. Geneva: World Health Organization (WHO); 2018.

29. El Achhab Y, El Ammari A, El Kazdouh $H$, et al. Health risk behaviours amongst school adolescents: Protocol for a mixed methods study. 2016;16(1):1-6. https:// doi.org/10.1186/s12889-016-3873-4

30. UNAIDS. Joint United Nations Programme on HIV/AIDS. 90-90-90, an ambitious treatment target to help end the AIDS epidemic. Geneva; 2014

31. National Department of Health. Universal test and treat. Pretoria; 2016.

32. National tuberculosis management guidelines. Tshwane: South African National Department of Health; 2014.

33. Arnoldussen M, Schimmel H, Op de Coul E, Van den Hof S, De Vries G. Tuberculosis patients with unknown HIV status in the Netherlands: Analysing underreporting and lack of testing. 2017;50(5):1701257. https://doi.org/10.1183/13993003.012572017

34. Long R, Niruban S, Heffernan C, et al. A 10-year population based study of 'optout' HIV testing of tuberculosis patients in Alberta, Canada: National implications. PLoS One. 2014;9(6):e98993. https://doi.org/10.1371/journal.pone.0098993

35. Tanue EA, Nsagha DS, Njamen TN, Assob NJC. Tuberculosis treatment outcome and its associated factors among people living with HIV and AIDS in Fako division of Cameroon. PLoS One. 2019;14(7):e0218800. https://doi.org/10.1371/journal. pone. 0218800

36. Engelbrecht M, Kigozi N, Chikobvu P, Botha S, Van Rensburg H. Unsuccessful TB treatment outcomes with a focus on HIV co-infected cases: A cross-sectional retrospective record review in a high-burdened province of South Africa. BMC Health Serv Res. 2017;17(1):470. https://doi.org/10.1186/s12913-017-2406-x

37. Khazaei S, Hassanzadeh J, Rezaeian S, et al. Treatment outcome of new smear positive pulmonary tuberculosis patients in Hamadan, Iran: A registry-based cross-sectional study. Egypt J Chest Dis Tuberc. 2016;65(4):825-830. https://doi. org/10.1016/j.ejcdt.2016.05.007

38. Kirenga BJ, Levin J, Ayakaka I, et al. Treatment outcomes of new tuberculosis patients hospitalized in Kampala, Uganda: A prospective cohort study. PLoS One. 2014;9(3):e90614. https://doi.org/10.1371/journal.pone.0090614

39. First Global Plan to End TB Progress Report shows need for huge efforts and scale up to 90-(90)-90 TB targets. Geneva: Stop TB Partnership; 2019. Available from http://www.stoptb.org/news/stories/2017/ns17_060.asp

40. Ketema K, Raya J, Workineh T, Klinkenberg E, Enquselassie F. Does decentralisation of tuberculosis care influence treatment outcomes? The case of Oromia region,
Ethiopia. Public Health Action. 2014;4(3):S13-S17. https://doi.org/10.5588/ Ethiopia. Public
pha.14.0059

41. Li X, Yang Y, Liu J, et al. Treatment outcomes of pulmonary tuberculosis in the past decade in the mainland of China: A meta-analysis. Front Med. 2013;7(3):354-366. https://doi.org/10.1007/s11684-013-0257-3

42. Wen $Y$, Zhang Z, Li X, et al. Treatment outcomes and factors affecting unsuccessful outcome among new pulmonary smear positive and negative tuberculosis patients in Anqing, China: A retrospective study. BMC Infect Dis. 2018;18(1):104 $\mathrm{https}: / /$ doi.org/10.1186/s12879-018-3019-7

43. Izudi J, Semakula D, Sennono R, Tamwesigire IK, Bajunirwe F. Treatment success rate among adult pulmonary tuberculosis patients in sub-Saharan Africa: A systematic review and meta-analysis. BMJ Open. 2019;9(9):e029400. https://doi. org/10.1136/bmjopen-2019-029400

44. Budgell E, Evans D, Schnippel K, Ive P, Long L, Rosen S. Outcomes of treatment of drug-susceptible tuberculosis at public sector primary healthcare clinics in Johannesburg, South Africa: A retrospective cohort study. S Afr Med J. 2016;106(10):1002-1009. https://doi.org/10.7196/SAMJ.2016.v106i10.10745

45. Mlotshwa M, Abraham N, Beery M, et al. Risk factors for tuberculosis smear nonconversion in Eden district, Western Cape, South Africa, 2007-2013: A retrospective cohort study. BMC Infect Dis. 2016;16(1):365. https://doi. org/10.1186/s12879-016-1712-y

46. Santha T, Garg R, Frieden TR, et al. Risk factors associated with default, failure and death among tuberculosis patients treated in a DOTS programme in Tiruvallur District, South India, 2000. Int J Tuberc Lung Dis. 2002;6(9):780-788.

47. Berkowitz N, Okorie A, Goliath R, Levitt N, Wilkinson RJ, Oni T. The prevalence and determinants of active tuberculosis among diabetes patients in Cape Town, South Africa: A high HIV/TB burden setting. Diabetes Res Clin Pract. 2018;138:16-25. https://doi.org/10.1016/j.diabres.2018.01.018

48. Peer N, Kengne A-P, Motala AA, Mbanya JC. Diabetes in the Africa region: An update. Diabetes Res Clin Pract. 2014;103(2):197-205. https://doi.org/10.1016/j. diabres.2013.11.006 